\title{
PODER, MEMORIA Y SUJETO EN TIKAL FUTURA. MEMORIAS PARA UN FUTURO INCIERTO (NOVELITA FUTURISTA) DE FRANZ GALICH
}

\begin{abstract}
Patricia Alvarenga Venutolo*
Resumen: El presente artículo se propone enriquecer la reflexión acerca de la obra Tikal Futura haciéndola dialogar con la literatura sociológica e histórica sobre el mundo guatemalteco contemporáneo, así como con propuestas analíticas relacionadas con la construcción de la subjetividad. Tres dimensiones de Tikal Futura son profundamente exploradas. La primera utiliza los conceptos de "otredad" y de "abyección" para profundizar en las posibilidades que ofrece la representación literaria de la dinámica generada por el incesante crecimiento de las distancias asimétricas, tanto físicas como simbólicas, que caracteriza la historia guatemalteca. La segunda sección refiere al poder y su relación con las subjetividades. La "banalidad del mal" es una útil herramienta analítica para explorar los efectos del poder en las subjetividades, no solo entre sus víctimas sino también entre sus sujetos victimarios. En la última sección el concepto de "memoria" es central en el análisis de un texto donde el pasado es expresión vital del presente, es decir, es el espacio simbólico que ofrece potencialidades liberadoras.
\end{abstract}

Palabras clave: Identidad, poder, memoria, literatura, Franz Galich, Guatemala.

\begin{abstract}
The current article enriches the reflection about the novel Tikal Futura, through the dialogue between such novel and the sociological literature related to Guatemalan society and theoretical analysis around the issue of subjectivity. La first section explores the literary representation of social exclusion through the concepts of "otherness" and "abjection". The second one develops the relation between power and subjectivity taking under consideration their effects in the victims as well as in the victimizer. The concept of memory is central in the last section because in the novel the representation of the past is a key issue in the creation of effective forms of resistance.
\end{abstract}

Keywords: identity, power, memory, literature, Franz Galich, Guatemala.

Fecha de recepción: 13/10/15 - Fecha de aceptación: 11/02/16

* Costarricense. Doctora en Historia por la Universidad de Wisconsin, Madison, EE. UU. Profesora e investigadora de la Escuela de Historia de la Universidad Nacional (UNA). Directora de la Maestría en Historia Aplicada de la UNA. Correo electrónico: patriciaalvarengavenutolo@gmail.com 
7 ikal Futura. Memorias para un futuro incierto (novelita futurista), de Franz Galich, es una obra situada en un futuro distante, pero cuyos fundamentos están profundamente enraizados en el presente. Obra póstuma e inconclusa, cuyo inicio data de 1999, es decir, a escasos años de los Acuerdos de Paz que, en 1996, concluyeron con la guerra que libró el Estado guatemalteco contra la insurgencia en Guatemala; pero que, en realidad, estuvo dirigida contra quienes osaran cuestionar el orden establecido e incluso contra aquellas personas que podrían ser potenciales colaboradoras de sus contendientes. El Estado volcó su potencial destructivo sobre múltiples comunidades indígenas, como respuesta a la sospecha, no siempre fundada, de que en estas había gente implicada en el movimiento armado.

La obra de Galich se ubica, según Werner Mackenbach, "en un presente omnipotente". "Tikal Futura es una reflexión ficcional acerca del poder que se proyecta al pasado y al futuro, a través de la muerte, la impunidad, la injusticia y la traición. Pero esta última, no deviene de las altas esferas, sino del propio mundo de quienes viven cotidianamente la opresión y la injusticia. En la obra se trata de una constante histórica, que erosiona las potencialidades de resistencia de quienes podrían abrir las vías de la imaginación a un futuro que trascienda la repetición incesante de una historia infame. En la narrativa de Galich, pasado, presente y futuro se entrelazan. El mañana está implícito en el mundo que hoy se construye. El imperio de la impunidad, la sistemática respuesta del Estado a los desafíos ciudadanos, no con razones sino con armas, el ancestral racismo que llevó a callar a quienes podrían tener voz frente el drama de las masacres indígenas y las distancias abismales entre las clases sociales que cada día se agigantan más, no avizoran un futuro promisorio. ${ }^{2}$ Tikal Futura... propone que ese presente de horror y de injusticia se reproduce y magnifica cuando se sella un acuerdo entre las partes contendientes, que lejos de objetar ese pasado ominoso, lo esconde y niega. El olvido y la impunidad impiden que cambie lo esencial: esas subjetividades construidas a partir del odio y el desprecio a las otras personas.

En las siguientes páginas exploramos tres dimensiones de la obra: la construcción de las otredades, el poder y la memoria. El primer apartado analiza la representación de un mundo en el que las inconmensurables distancias sociales se corresponden con la planificada división de los espacios ocupados por sus legítimos sujetos habitantes y aquellos condenados a la marginalidad y al abuso. Intentamos ingresar en las estrategias que transforman al otro ser en mero objeto de producción y de placer, erotizando el poder del abuso sexual, y de la

1 Werner Mackenbach, "Tikal futura. Novela póstuma de Franz Galich”, El Nuevo Diario, 3 de octubre de 2012: http://www.elnuevodiario.com.ni/

2 Edelberto Torres-Rivas, Revoluciones sin cambios revolucionarios (Guatemala, Guatemala: F\&G Editores, 2011); Roddy Brett, Una guerra sin batallas. Del odio, la violencia y el miedo en el Ixcán y el Ixil (1972-1983) (Guatemala, Guatemala: F\&G Editores, 2007). 
destrucción física de sus cuerpos. El concepto de abyección desarrollado por Julia Kristeva es útil para analizar cómo en la obra se resemantiza el sentido de lo sucio y lo bajo. Es en aquel mundo rechazado como "abyecto" donde surge la esperanza; mientras que quienes se empeñan en negar su animalidad solo poseen el rostro monstruoso que el poder les ha impreso.

El segundo apartado se concentra en la exploración de las dinámicas del poder. Los sujetos excluidos y los privilegiados, aunque de diferente manera, son sometidos a diversas estrategias de poder destinadas a eliminar toda voluntad humana. En esta sección se reflexiona acerca de esos sujetos de Ciudad de Arriba que, si bien aparentemente son dueños de sus vidas y de las vidas de los otros, en realidad son el producto de una respuesta unívoca y obediente al poder invisible y omnímodo. Si bien en Tikal futura están presentes conceptos desarrollados por Michel Foucault como el panóptico de Bentham, la obra va más allá de la sociedad disciplinaria que este describe para mostrar el rostro adusto de un poder fundamentado en el aniquilamiento del sujeto. En esta dirección, la idea de "la banalidad del mal" de Hanna Arendt resulta reveladora para aprehender esas subjetividades vaciadas de sí en las que el mal se asienta sin problema. Ciudad de Abajo constituye un universo fuertemente custodiado, dominado a través de la vigilancia permanente, la violencia brutal y la propagación de drogas que eliminan por completo la voluntad. Sin embargo, el poder no ha logrado arrasar al sujeto. Es allí donde aparece la esperanza de la resistencia.

El tercer apartado versa sobre la memoria desde dos ángulos distintos: el primero refiere al papel de la historia. Esta no es la búsqueda de un pasado que ha muerto, es más bien expresión vital del presente. El universo social construido a través de los siglos vive en la experiencia cotidiana. Por ello esta obra futurista nos conduce recurrentemente a la reflexión sobre la historia y, por supuesto, sobre un presente donde se están colocando piedras angulares que dan sustento al mundo de Tikal futura. La visión cíclica del tiempo es la clave para explicar la dinámica de la historia. El mundo narrado es un producto de los tiempos anteriores. La segunda vía de interés tiene que ver con la memoria como elemento fundante de la subjetividad, recurso imprescindible para la generación de resistencias articuladas frente al poder. Nelly Richard nos habla de esa memoria petrificada en monumentos, contraponiéndola a la memoria activa de quienes buscan en ella la construcción de nuevos sentidos de vida, la posibilidad de ir más allá de lo permitido. Ese pasado en Tikal futura se convierte en estrategia vital para destruir un presente ominoso, reconstituyendo la historia.

\section{Argumento de la obra}

Cuahutemallán es una sociedad con profundas escisiones sociales donde los que pueblan Ciudad de Arriba han perdido todo sentido de humanidad. 
Solo la muerte logra poner límites a la despiadada explotación económica y sexual que ensayan los "legítimos habitantes" sobre el mundo de los descartables, ubicados en Ciudad de Abajo, también llamada Ciudad Miseria y Xibalbá. El sistema neoliberal desarrollado en nuestros tiempos sobrevive en los siglos venideros y en Tikal futura ..., no cuenta con rivales que disputen su dominio. En la narración, dos escenarios se contraponen sistemáticamente: las conversaciones del embajador de Quisyan, Mr. Klimowitz y el alto funcionario Apocalíptico y las narrativas del mundo de los descartables, centradas en la familia de la abuela Cané y sus nietos: Ix y Namú. En Ciudad de Abajo, desde el nacimiento, sus habitantes llevan instalada una micro cámara en el cerebro, la cual permite el control de sus conversaciones y movimientos físicos. Además, les administran masivamente las drogas Opsin y Rogua, para que pierdan la voluntad y estimularles a trabajar arduamente hasta perder sus capacidades físicas. Entonces, se convierten en descartables.

La abuela Cané tiene la misión de preservar la memoria del mundo indígena que deberá transmitir a otra persona en espera del Gran Día. En una clara alegoría a la obra de ficción Fahrenheit $451,{ }^{3}$ ella ha debido memorizar textos emblemáticos como el Popol Vuh y guarda celosamente sus escritos que ha titulado "Memorias para un futuro incierto". En estos registra los acontecimientos de los pueblos indígenas cuyo recuerdo para el resto de la población apenas subsiste fragmentariamente en el racismo y en algunos de sus símbolos, transformados violentamente en objetos exotizados. La abuela Cané, además de ser depositaria de la memoria, tiene el don de advertir el destino de quienes la rodean. Ella conoce el trágico final que espera a su querido nieto Namú.

Apocalíptico y Klimowitz hacen negocios mientras consumen whisky y drogas de alta calidad en "El eros de Acuario". Las prácticas sexuales que allí se ejecutan son, en principio, prohibidas por el poder omnímodo e invisible de Ciudad de Arriba que promueve formas "limpias" de placer donde no hay encuentros entre los cuerpos. Sin embargo, en realidad Eros se encuentra en manos del Servicio SuperSecreto y es utilizado para controlar a sus usufructuarios. Los legítimos habitantes asisten allí atraídos por una oferta impresionante de posibilidades de disfrute sexual. La imaginación no tiene límites en la creación de nuevas rutas hacia el placer, donde se combinan prácticas hetero y homosexuales. De estas últimas también disfruta Apocalíptico, quien se autodefine como "muy macho". Compartiendo con el embajador los placeres que Eros le ofrece, intenta convencerle de que invierta en su propuesta de negocios: "La ruta Maya. Mega Proyecto. Tikal Futura. Fase II". Esta ofrecerá creativos entretenimientos para turistas provenientes del norte, tales como guerras revolucionarias en vivo en las que la clientela podrá aniquilar guerrilleros de carne y hueso. Así mismo,

3 Ray Bradbury, Fahrenheit 451 (New York, EE. UU.: Ballantine Books, 1953). 
podrán llevar a cabo cacería de mujeres en Ciudad de Abajo para el disfrute sexual, cacerías que ya son habituales entre los pobladores de Ciudad de Arriba, donde la práctica de la inoculación forzosa de la droga hace que su erótico objeto de caza pierda por completo su voluntad, para responder sin resistencia alguna a las demandas de sus amos ocasionales. Al despertar, las mujeres utilizadas como esclavas sexuales no recuerdan absolutamente nada de lo ocurrido.

La cíclica historia del mundo indígena que narra la abuela Cané converge en los primos Ix y Namú. Ellos se han enamorado sin saber que sus familias, aunque emparentadas, permanecieron en conflicto durante siglos. La memoria de la abuela transita una y otra vez por las luchas intestinas que facilitaron la derrota del mundo indígena: tukuches y cavek, cackchiqueles y quichés. De los "Ablabik" descienden los habitantes de Ciudad de Arriba, quienes pretenden ser "blancos" pues, como los sujetos ladinos actuales, se empeñan en negar la presencia de sangre indígena que aflora en sus cuerpos. ${ }^{4}$

Pero el poder omnímodo de Ciudad de Arriba tiene sus grietas. Los hermanos Vitz y Zacté viven en las profundidades de Ciudad Miseria. En el antiguo alcantarillado, su espacio vital, se han convertido en líderes del Ejército Revolucionario de Liberación de Ciudad de Abajo (ERLCIA). Ellos, por ser la escoria de la escoria, los desechos humanos de Ciudad de Abajo, se han librado del control del micro chip instalado en el cerebro, lo que les permite comunicarse sin tener que acudir a los artilugios que han debido crear el resto de habitantes de Ciudad de Abajo para hacerlo.

El juego de pelota, juego ritual de la antigua civilización maya, se practica, pero con sentidos distintos. Se trata de enfrentamientos de equipos integrados cada uno por dos personas que se movilizan en especie de motocicletas tras el dominio de la pelota. La ganadora tiene el derecho de decidir si su contrincante vive o muere. Los gemelos Namú y Balan deberán enfrentarse a los Gabilanes, representantes de los Ablabix cuyos nombres los retratan: Gabilán Sangriento y Garra de Sangre. Ambos asesinaron a traición a su padre y tío. En la obra nunca se lleva a cabo este enfrentamiento, aun cuando el lector experimenta la tensión por la expectativa de ese próximo encuentro, que no puede dejar de vincular con las trágicas visiones proféticas de la abuela Cané sobre el destino de Namú.

La seguridad de Ciudad de Arriba se encuentra en manos del indio Sacul, cuya crueldad no tiene límites. Apocalíptico y el embajador acuden a él para que realice secuestros masivos de descartables con destino al sacrificio en aras de satisfacer a los grupos turísticos con exóticos objetos de caza. Pero Sacul, entrenado en Quisyan, se les sale de las manos. Su sadismo lo lleva a perpetrar matanzas indiscriminadas acompañadas de actos de necrofilia y canibalismo. Escenas dantescas narran el horror a través de miles de descartables que convierten, en pocos

4 Franz Galich, Tikal futura. Memorias para un futuro incierto (novelita futurista) (Guatemala, Guatemala: F\&G Editores, 2012), 60. 
momentos, en montañas de cadáveres. En una clara alusión al papel de los Estados Unidos durante la guerra contrainsurgente, Sacul y los kaibiles que aparecen como parte de las fuerzas de seguridad, adquirieron el gusto por el sufrimiento del otro en centros de entrenamiento de Quisyan. En el mundo de Tikal futura el poder ha refinado sus formas de operación, pero tiene como claro fundamento el presente. El indisputable dominio del sistema neoliberal, la complicidad del país del norte en las represiones y masacres de la década de 1980, sigue vigente aún siglos después. Los actores de entonces continúan tan empoderados y dispuestos a masacrar a los grupos "descartables" como lo estuvieron en la segunda mitad del siglo XX. La obra concluye con la narración de un atentado del ERLCIA contra la central hidroeléctrica, con lo que nos hace saber que la resistencia está viva y, pese al avasallador poder al que se enfrenta, es efectiva.

\section{El presente del futuro: La Guatemala contemporánea}

Sostiene Edelberto Torres Rivas que en el conflicto armado de finales del siglo XX: "no hubo guerra civil sino un Estado terrorista, cuyos efectos son peores y los padece toda la sociedad ahora y en el futuro". ${ }^{5}$ Los actos de genocidio ocurridos entre 1981 y 1983 por parte del ejército y sus colaboradores en Huehuetenango, Quiché y Baja Verapaz, estuvieron acompañados de la violencia sexual contra mujeres y niñas, la esclavitud, la tortura, la destrucción despiadada y cruel de cuerpos y de los poblados y bienes que estos habitaron. ${ }^{6}$ El terror vivido por las comunidades arrasadas no despertó reacciones significativas "por una sociedad civil urbana, que estaba lejos, aterrorizada y desarticulada". $\mathrm{Al}$ lado de estas matanzas indiscriminadas, los cuerpos represivos se encargaron de silenciar, mediante el secuestro, la tortura y la muerte, tanto las resistencias armadas como aquellas que buscaron su expresión en el terreno de la vida política. Refiriéndose a los actores que desde la subalternidad creyeron que era posible cambiar el mundo en que habitaban, Torres Rivas asevera lo siguiente:

"En Guatemala no hubo nunca sindicalistas, líderes, militantes detenidos, juzgados, culpabilizados, la modalidad aplicada después de 1966 no utilizó las instituciones judiciales, o eran asesinados o desaparecidos, la política de terror no incluyó nunca presos políticos". ${ }^{8}$

Aun cuando Tikal futura muestra las formas de poder extremas ensayadas sobre el mundo subalterno, también abre posibilidades reflexivas acerca del

5 Edelberto Torres Rivas, "Prólogo. El terror no tuvo límites", en: Roddy Brett, Una guerra sin batallas..., XXXI. Las cursivas son nuestras.

6 Brett, Una guerra sin batallas..., 4-6.

7 Ibid, 226.

8 Torres-Rivas, 431. 
efecto que un sistema de dominación, sustentado en la exclusión y la muerte, tiene sobre quienes se consideran los legítimos habitantes. El desgarre en el tejido social de la sistemática aplicación de la violencia no deja incólumes a quienes creyeron mantenerse al margen de los acontecimientos. Esa crueldad que emana del Estado mismo se difumina en el espacio, encarnándose en las diversas subjetividades para multiplicarse y adquirir nuevas formas de expresión. Tampoco esta historia de horror y de silencios abrió espacios para que tantas décadas de sacrificio se transmutaran en mejores condiciones de vida para el mundo subalterno. Las oligarquías mantienen su poder y los partidos políticos son "maquinarias de corrupción y nepotismo". 9

Si bien, con los Acuerdos de Paz se abrió un horizonte inédito para las luchas indígenas en el terreno de la vida política, su presencia en el mundo público, según Rafael Chanchavac Cux, ha sido tolerada en cuanto no amenace los intereses de los poderosos. ${ }^{10}$ Roddy Brett señala que la democratización ha estado acompañada de "espacios de participación sin impacto" 11 destinados a cumplir con las demandas de la comunidad internacional. La década de 2000 mostró que la participación de líderes mayas en el Estado los ha distanciado de sus bases. ${ }^{12}$ Actualmente el racismo no se manifiesta con la violencia verbal del pasado. Sin embargo, Charles Hale, en su estudio situado en Chimaltenango, lo encuentra vigente en los discursos ambivalentes de población ladina que, por una parte, declaran repudiar el racismo; pero, en su narrativa, se aprecia que en realidad se encuentran profundamente permeados por las tradicionales asimetrías dicotómicas entre ladinos e indígenas. ${ }^{13}$

No obstante, pese a las profundas ambivalencias del proceso democrático, hay avances estimables. Santiago Bastos recuerda que a finales de la década de 1980 esos sujetos indígenas que se manifestaban para denunciar los actos genocidas eran "seres inexistentes reclamando por una represión inexistente [lo cual define] lo que era esa Guatemala en transición". ${ }^{14}$ Pero, de acuerdo con los autores citados, los alcances democráticos parecen ser inocuos, es decir, inofensivos

9 Santiago Bastos, "Prólogo. Los actores sociales en una década olvidada", en: Roddy Brett, Movimiento social, etnicidad y democratización en Guatemala (1985-1996) (Guatemala: F\&G Editores, 2006), XXVI.

10 Brett, Movimiento social..., 175.

11 Roddy Brett, "De movimiento indígena a complejidad política: la evolución de las políticas indígenas 1996-2007”, en: El movimiento maya en la década después de la paz (1997-2007), (comps.) Santiago Bastos y Roddy Brett (Guatemala, Guatemala: F\&G Editores, 2010), 72.

12 Santiago Bastos y Roddy Brett, "Introducción. Reevaluando nuestro conocimiento sobre la movilización política de los mayas", en: Bastos y Brett, El movimiento maya..., IX-XXII. "La política maya ya no la hacen 'activistas' mayas, sino 'gestores' mayas". Bastos, "La política maya en la Guatemala posconflicto", en: Bastos y Brett, El movimiento maya..., 24.

13 Hale utiliza la definición del neo-racismo de Etienne Balibar quien afirma que, si bien este repudia el concepto raza, reproduce sus potencialidades estigmatizadoras de alteridades, en la construcción simplificada, estática e invariable del concepto de cultura. Charles R. Hale, "Más que un indio”. Ambivalencia racial y multiculturalismo neoliberal en Guatemala. (Guatemala, Guatemala: AVANCSO, 2004), 188.

14 Bastos, "Prólogo. Los actores sociales en una década olvidada", en: Brett, Movimiento social..., XXIII. 
para el sistema neoliberal. La presencia del movimiento maya se ha concentrado en el terreno de la vida cultural y, desde la perspectiva de las tendencias actuales, parece estar perdiendo la vitalidad que le acompañó en sus primeros años. Por otra parte, tampoco en el terreno de las luchas contra la discriminación los resultados son plenamente satisfactorios. Hale muestra las profundas fisuras del discurso "políticamente correcto" de la población ladina actual en torno a la convivencia entre culturas.

Sin embargo, Edgar Esquit sugiere que quizá el espacio más productivo de las resistencias no se encuentra en las luchas mayas a nivel nacional, sino en movilizaciones indígenas locales. En Comapala, jóvenes que no están vinculados con los poderes hegemónicos, han logrado construir una narrativa propia del pasado de la comunidad a partir de la pintura. Este movimiento, aunque vinculado al desarrollo del turismo y fundado en visiones esencialistas que, según Esquit, limitan la construcción de alianzas, hace recordar que lo maya tiene "significados múltiples" que, agregaríamos, contribuyen a la creación de nuevos espacios para el desarrollo de resistencias a la hegemonía. ${ }^{15}$ Es decir, una mirada focalizada en esfuerzos comunitarios independientes visibiliza nuevas potencialidades de la movilización indígena. Ese universo social, visto en su conjunto, parece clausurar las posibilidades de incidencia de los grupos subalternos. Sin embargo, en el microcosmos de la comunidad, la creatividad colectiva abre nuevas posibilidades de reflexión, aflora la esperanza de que la lucha por un mundo mejor aún sea posible.

Tikal futura ofrece una mirada pesimista sobre el futuro del país y del mundo, aunque en la narrativa la resistencia y la solidaridad humana constituyen una pequeña luz de esperanza en medio de las múltiples manifestaciones de la violencia que genera la deshumanización de los grupos excluidos, y que termina por vaciar de todo contenido humano las vidas de quienes se encuentran entre la legítima "ciudadanía".

\section{Un universo de distancias abismales}

La ciudad-modelo es la propuesta más acabada que hoy existe para la segmentación de los grupos sociales en espacios geográficamente separados. En estas nuevas urbes se impide el acceso a quienes podríamos llamar, parafraseando a Galich, descartables. Su ciudadanía cuenta con todos los servicios requeridos en tales "metrópolis privadas creadas desde cero, con personalidad jurídica y administración propia". ${ }^{16}$ De tal forma, quienes las habitan no tienen necesidad de

15 Edgar Esquit, "Movilización política indígena en Comalapa en la era de la paz: Identidades, memorias y autodeterminación indígena en la localidad", en: Bastos y Brett, El movimiento maya ..., 233-265.

16 "Ciudades modelo pueden significar empobrecimiento para Honduras", El Heraldo, 31 de octubre de 2014: www.elheraldo.hn/esp/mediapool/sites/El Heraldo/Pais/ 
mezclarse con el mundo sucio y violento que les rodea. Esta propuesta se concreta en 2011, años después de que Tikal futura fuera escrita. No por casualidad es en Honduras donde la clase política junto con el capital nacional y transnacional están impulsando su creación. Este es un país profundamente polarizado con una de los mayores índices de pobreza y de criminalidad de América Latina, donde la histórica corrupción del ejército y de la policía hace tan temibles las instituciones del orden como a las organizaciones criminales. ${ }^{17}$ Pero si bien Honduras es el país líder en esta iniciativa, en 2016 en Guatemala se encuentra en proceso de construcción una "ciudad privada" para sectores adinerados, donde estos podrán encontrar toda clase de servicios perfectamente resguardados del espectáculo de la miseria y de la violencia prevaleciente en el resto del país. ${ }^{18}$ En efecto, frente a ese futuro oscuro y, parafraseando a Galich, bastante incierto para las mayorías, la ciudad modelo se erige como el proyecto que resguarda el ideal de la modernidad del orden y del progreso, expulsando de su seno todo aquello que ensucia, afea y perturba la simetría de la urbe. Pero esta expulsión de los otros grupos internos, como lo muestra Galich en su obra, termina por vaciar de contenido humano esas subjetividades forjadas a partir de la profundización de las distancias asimétricas con la alteridad.

Refiriéndose a la ciudad de México, Guadalupe Carrillo sostiene que "los contrastes son hoy en esta megaciudad los mejores adjetivos para clasificarla". ${ }^{19}$ Desde el poder político y económico, hay una búsqueda ansiosa, no siempre fructífera, por separar radicalmente la belleza y la opulencia de la fealdad y la miseria. En Tikal futura las dos ciudades expresan el triunfo absoluto de la segregación de lo feo, lo pobre y lo sucio, de aquello considerado bello, opulento y limpio. Cuando se fundaron las dos ciudades, se permitió habitar el espacio citadino privilegiado a las personas "más blancas", educadas y exitosas

17 "El proyecto ha superado los escollos de las resistencias y hoy parece avanzar con paso firme. Espacios de mil metros cuadrados en las costas serán reservados para la creación de cada ciudad modelo, lo que haría desaparecer a 24 comunidades garífunas". Tomás Andino, "Ciudades modelo no, sociedades modelo s'́, ALAI. Agencia Latinoamericana de Información, 19 de enero de 2011: http://www.alainet.org/active/43664. El 21 de enero de 2011 dos días después de que el congreso hondureño aprobara por unanimidad la creación de la primera ciudad modelo de Centroamérica, el presidente Porfirio Lobo, aplaudiendo la iniciativa, afirmó lo siguiente: "Yo invito a mi pueblo a soñar por vivir en un lugar ideal, sin delincuencia, en un territorio autónomo y con un mejor sistema educativo y de salud". De acuerdo con este anónimo reportaje, Lobo también señaló que "en la ciudad modelo se instalarán fábricas de computadoras, turbinas de aviones, barcos de gran calado, ensamblaje de carros y otros negocios de envergadura. Las compañías extranjeras que operen en esos lugares tendrán concesiones estatales por más de 20 años y los resultados se concretarían en cinco". "Aprueban primera Ciudad Modelo de Centroamérica", en: Empresa de Gestión y Planificación Municipal, 21 de febrero de 2011: http://gestionterritorialmuncipal.blogspot.com/2011/01/ aprueban-primera-ciudad-modelo-de.html

18 "Ciudad privada para los ricos en Guatemala", La Opinión, 8 de marzo de 2016: http://www.laopinion. com/2013/01/08/ciudad-privada-para-los-ricos-en-guatemala-fotos/

19 Guadalupe Isabel Carrillo Torea, Miradas a la ciudad. La representación del imaginario urbano en el discurso literario latinoamericano de mediados del siglo XX (Toluca, México: UAEM, 2011), 168. 
económicamente. ${ }^{20}$ La distancia asimétrica entre población más blanca y menos blanca se expresa en la colocación espacial de ambas urbes: "Ciudad Arriba se yergue mil metros más arriba para no mezclarse con los descartables de Ciudad de Abajo. Arriba el aire es limpio y transparente". ${ }^{21}$ Parodiando el título de la famosa obra de Carlos Fuentes, continúa aseverando el narrador, "la región más transparente le dicen sus aduladores y poetas". ${ }^{22}$ Tikal futura inicia con la imagen del "color Coca-Cola que invade toda la Ciudad de Abajo". ${ }^{23}$ Ese color Coca-Cola se repite a lo largo de la obra. Sin embargo, quienes viven rodeados de las oscuras tonalidades de esa bebida, nunca la han podido probar pues es exclusiva para habitantes de la Ciudad de Arriba. Galich se apropia de la imagen de la Coca Cola, tradicionalmente vinculada, por la crítica, al neoliberalismo e imperialismo, con el poder hegemónico de los Estados Unidos y fuertemente cuestionada por sus efectos en la salud. El color Coca-Cola como símbolo de la contaminación sugiere la suciedad del poder del norte $\mathrm{y}$, a la vez, aquella que se posesiona de los cuerpos que la ingieren. ${ }^{24}$

La Ciudad de Abajo cuenta con infraestructura absolutamente obsoleta, sus habitantes trabajan en fábricas por magros salarios y, cuando su salud ha sido destruida por las drogas suministradas masivamente y por las condiciones de vida, se convierten en individuos descartables que viven entre los desperdicios de la ciudad. Pero todo el conjunto de Ciudad Miseria está impregnado por el abandono, la suciedad; sus calles, cubiertas de aguas putrefactas provenientes de la vieja red de alcantarillado. En cambio, en Ciudad de Arriba, sus habitantes disfrutan de excelente infraestructura y, aunque no se dice explícitamente, la narración sugiere, viven en un mundo aséptico. Desde el poder se promueve el disfrute sexual sin la contaminación de los cuerpos. Proserpina, la esposa de Apocalíptico, se horroriza al sospechar que su esposo "fornica de la manera antigua". ${ }^{25}$ Se trata de una retórica hipócrita que alimenta el abuso generalizado de las mujeres que provienen del mundo inferior.

El repudio al contacto sexual no está de ninguna manera superado en nuestras sociedades. Encuentra sus fundamentos tanto en el cristianismo como en la filosofía moderna. Sostiene Julia Kristeva que Hegel y Kant, pese a sus distancias interpretativas en torno a lo impuro, comparten "su condena de la impureza (sexual). Coinciden en su objetivo de mantener la conciencia separada

\footnotetext{
20 Galich, 126.

21 Ibid, 125.

22 Ibid.

23 Ibid, 11.

24 Véase por ejemplo: Ana Fiol, "El producto negro, un símbolo del imperialismo", Rebelión, 21 de diciembre de 2003: http://www.rebelion.org/hemeroteca/plancolombia/031221fiol.htm. "Cuán malo es para la salud el componente que Coca Cola retira de sus bebidas", BBC Mundo, 6 de mayo de 2014: http://www. bbc.co.uk/mundo/noticias/2014/05/140506_salud_aceite_vegetal_bromado_gtg

25 Galich, 149.
} 
de la impureza que, sin embargo, la constituye dialécticamente". ${ }^{26}$ En este universo narrativo Ciudad de Arriba busca expulsar la abyección, colocándola en Ciudad Miseria. Reciclables, sucios, objetos de disfrute sexual, hacinados como basura, estos individuos viven en medio de excrementos. Kristeva encuentra en la abyección, aquello de nosotros mismos o de nosotras mismas que rechazamos por cuanto perturba una imagen coherente de nuestra identidad. Lo abyecto se relaciona con la impureza. Según la autora, esta es perturbadora en cuanto "el excremento y sus equivalentes - putrefacción, infección, enfermedad, cadáver, etc.- representan el peligro proveniente del exterior de la identidad: el yo (moi) amenazado por el no-yo (moi), la sociedad amenazada por su afuera, la vida por la muerte". ${ }^{27}$ Pero el sentido de la abyección es polivalente, se proyecta metonímicamente en los espacios de la vida social, pues "lo puro será aquello que corresponde a una taxonomía establecida; lo impuro, aquello que la perturba, que establece la mezcla y el desorden". ${ }^{28}$ Lo abyecto de nuestro cuerpo es proyectado en otros seres: mujeres, clases inferiores, minorías étnicas.

Basándose en estudios antropológicos, Kristeva sostiene que el conjunto social "a partir de una simple lógica de exclusión de lo sucio que, promovido así al estatuto ritual de impureza, fundaría lo 'propio' de cada grupo social, cuando no de cada sujeto". ${ }^{29}$ Es decir, la abyección es una construcción histórica que siempre va acompañada de la violencia, pero que adquiere sus características peculiares en cada sociedad. En Tikal futura lo impuro se proyecta a Ciudad Miseria. Pero, precisamente, ese imaginario de suciedad del acto sexual está vinculado a la construcción de deseos sexuales aberrantes. La violación de las mujeres del mundo bajo es uno de los deportes favoritos de los hombres del mundo alto. Pero si abajo está lo sucio y lo descartable; los sentimientos humanos de amor, solidaridad y resistencia, surgen de este mundo de inmundicia. Los hermanos Vitz y Zacté, líderes del Ejército Revolucionario de Liberación de Ciudad de Abajo (ERLCIA), viven "en las profundidades de Ciudad Miseria, entre el anticuado sistema de alcantarillado". ${ }^{30}$ Sus aguas salían al lago Naltitama, "refugio de fieras, sabandijas e indigentes". ${ }^{31}$ En el lugar de la abyección está la salvación posible. En fin, la obra evidencia la violencia de la abyección invirtiendo los sentidos que las más diversas sociedades han otorgado a la pureza y su opuesto.

Los sujetos habitantes de Ciudad de Arriba, vaciados de subjetividad, son simples instrumentos manipulables del poder. Pero no por ello poco peligrosos. Apocalíptico debe su sobrenombre no solo a "lo que anuncia-desgracia tras

26 Julia Kristeva, Poderes de la perversión. Ensayo sobre Louis-Ferdinand Céline (México, D.F.: Siglo XXI Editores, 1989), 43.

$27 \mathrm{Ibid}, 96$.

28 Ibid, 132.

29 Ibid, 88.

30 Galich, 58.

31 Ibid. 
desgracia-. Él mismo es una desgracia exitosa". 32 "Desgracia exitosa" porque su éxito está en la destrucción de los otros seres, pero también porque en su éxito está su profunda deshumanización.

En el universo de Tikal futura no hay posibilidades de interacción social entre respetables y descartables. Estos últimos grupos se usan para producir riqueza y placer. Ningún gesto de comunicación es posible. En la mirada del mundo de los individuos legítimos, los descartables no tienen ni voz ni expresividad corporal. La abuela Cané, señala: "para ellos somos unos puntitos que miran en la distancia". ${ }^{33}$ La segregación espacial contribuye a afirmar las distancias identitarias. Ese otro individuo no se mira, se usa. Nal Chí, uno de los descartables en la resistencia armada, decía: "para ellos nosotros no existimos, nos miran peor que parias: somos los invisibles". ${ }^{34}$ La distancia inmensa entre las dos ciudades actúa como metáfora de las distancias inconmensurables entre sujetos privilegiados y descartables. La gente del mundo bajo, como objetos despreciables, representan una otredad radical.

\section{El poder sin rostro}

Apocalíptico ocupa un alto cargo de poder: es diputado suplente del Gran Congreso y aspira a llegar a ser presidente de Cuahutemallán. Sin embargo, él es una expresión de la forma en que opera el poder, no la encarnación del poder mismo. Si bien es capaz de utilizar a su antojo las vidas de descartables, se encuentra sometido a permanente vigilancia y no deja de temer que el complejo sistema que pretende espiar todos los espacios de su vida descubra sus violaciones a los interdictos y, especialmente, su procedencia originaria. Aún en su espacio favorito, el Eros de Acuario, Apocalíptico no disfrutaba plenamente de la gama de placeres que allí se ofertaba ya que, sostiene el narrador, "se sentía observado. Mejor dicho, se sabía observado, pues todo mundo sabía que el Tribunal Supremo (TS) todo lo sabía. No había nada ni nadie que escapara a su vigilancia". ${ }^{35}$ Más adelante, la obra ofrece mayores detalles del espacio del placer como espacio de control: "El Apocalíptico sabía que en ese lugar se espiaba a todo mundo, que existían los más sofisticados métodos e instrumentos, que las androides a la vez que prestaban servicios sexuales, también espiaban. Lo mismo las jovencitas de carne y hueso, aunque éstas eran más fáciles de engañar. Con las androides simplemente no había que pensar" ${ }^{36}$ Ese poder omnímodo, tema recurrente de la ciencia ficción del siglo XX, hiperboliza los complejos y diversos espacios so- 
ciales desde los que se despliega el poder en la modernidad. Sistemas panópticos de vigilancia acompañan el desarrollo de instituciones generadoras de disciplinas que forman y regulan los cuerpos y sus operaciones. ${ }^{37}$

El poder orienta, establece límites dentro de los cuales opera el sujeto. En Cuahutemallán esos instrumentos para vigilar las actuaciones y controlar su forma de operar en el mundo han llegado a un alto nivel de perfeccionamiento. El "saberse vigilado" expresa una forma de poder que, aun en el acto transgresivo, orienta la acción, no la determina, pero hace que se desenvuelva en un marco de posibilidades. No obstante, en Tikal futura la reflexión sobre el poder va más allá de la visión foucaliana. Este ya no solo opera para transformar sujetos y orientar sus acciones. Tiene un rostro perverso. Los individuos legítimos habitantes de Ciudad de Arriba no dejan de encontrarse sometidos a las asimetrías de poder. El abuso sexual es la norma entre las jefaturas. Eros de Acuario es un espacio ambivalente. Es creado desde el poder y en ese sentido podría considerarse un centro de construcción de disciplinas sociales. En efecto, el erotismo es orientado hacia el aniquilamiento de la voluntad de las mujeres convertidas en objeto sexual; erotismo que, en relación metonímica, se expresa en el deseo por la explotación y destrucción de los otros seres. Eros en realidad es un instrumento clave en la producción subjetiva que emana desde el poder.

Pero no se trata de que la transgresión se haya transformado en aquiescencia. Más bien, el límite de lo aceptable y lo inaceptable se ha vuelto difuso. El poder incentiva acciones que contradictoriamente sanciona y, por tanto, se vive permanentemente en el peligro de caer en sus garras. La perversidad distorsiona las lógicas disciplinarias creadoras de cuerpos productivos. Haciendo uso del doble discurso, conduce intencionalmente al sujeto a "lecturas erradas" de lo que los hombres de poder esperan de sí. La inseguridad y el miedo, siempre presentes, son innombrables, pues quien osa articular estas palabras puede fácilmente traspasar el umbral que conduce a la exclusión y a la muerte. ${ }^{38}$ Desarrollar un sentido común que permita desenvolverse entre las múltiples trampas es indispensable para la sobrevivencia, aunque no puede garantizarla. Cuando el poder decide purgar, encontrará en el sujeto subalterno lo que Baczko llama una "deuda de sentido con respecto al que detenta y es distribuidor supremo del sentido...". ${ }^{39}$

Un subordinado, flaco, temerosamente se dirige a su jefe, el indio Sacul, para relatarle lo que sabe, gracias a que indagó más allá de lo que él le solicitó,

37 "Lo que hace que el poder se aferre, que sea aceptado, es simplemente que no es solamente como una fuerza que dice no, sino que de hecho circula, produce cosas, induce al placer, forma saber, produce discursos; es preciso considerarlo más como una red productiva que atraviesa todo el cuerpo social...". Michel Foucault, "Verdad y poder", en Michel Foucault, Michel Foucault. Estrategias de poder. Obras esenciales. Volumen II (Barcelona, España: Ediciones Paidós, 1999), 48.

38 Véase el estudio del estalinismo que realiza Bronislaw Baczko en su libro Los imaginarios sociales. Memorias y esperanzas colectivas (Buenos Aires, Argentina: Ediciones Nueva Visión, 1991), 137-152.

39 Ibid, 146. 
sobre los atentados de la insurgencia y, la serie de asesinatos de descartables seguidos de necrofilia y canibalismo en los que su jefe estaba involucrado. Sacul, temiendo ser descubierto, lejos de celebrar el buen trabajo que su subalterno realizó, lo sanciona condenándolo a "cincuenta varejonazos a nalga pelada", ${ }^{40}$ castigo que infantiliza al transgresor; pero no lo conduce a la adultez sino a la muerte. Sin embargo, Sacul también es víctima de estas estrategias perversas de poder. Su superior Napichú tenía una forma peculiar de conducirse, "decía dos cosas contradictorias al mismo tiempo, luego observaba la actitud del interlocutor y así se formaba un juicio acerca de él". ${ }^{41}$ Tales juicios provenientes de un método caprichoso de lectura del otro podían tener efectos devastadores entre sus interlocutores subalternos. El temor de hallarse permanentemente en la cuerda floja inhibe la articulación de una reflexión frente a lo vivido.

En Ciudad de Arriba, como en la sociedad estalinista analizada por Baczco, el poder parece alcanzar el momento más totalizador y espeluznante cuando "cada individuo se encuentra completamente solo" 42 frente a ese monstruo, cuyo verdadero rostro no puede ser aprehendido. Si bien el poder panóptico construye sujetos, no cierra del todo las vías a la resistencia. Por el contrario, cuanto más invade espacios de la subjetividad, más parecen ampliarse sus horizontes. Esas "prácticas de sí" estudiadas por Foucault, se encuentran sin duda permeadas por el poder; pero son también espacios íntimos en los que el ser humano encuentra la posibilidad de reflexión, de ver el mundo de otro modo y de invención de otras posibilidades de ser. ${ }^{43}$

Apocalíptico, en su privilegiada posición social y política, es un sujeto funcional al sistema. Toma decisiones, crea estrategias que impulsan el desarrollo del capital, que fortalecen los cimientos mismos de su sociedad. Sin embargo, él es realmente un prisionero del poder. Le interesa sortear sus trampas, pero no para resistir. Cada movimiento que hace en ese sentido alimenta la fuerza de ese Argos cuya mirada panóptica se ha perfeccionado hasta el límite de lo imaginable. Apocalíptico elige posibilidades de acción, ${ }^{44}$ pero en su subjetividad no hay espacios para trascender el poder. El erotismo aniquilador no se concentra exclusivamente en la sexualidad, invade la vida social. El deseo de someter, aniquilar, destruir al otro ser se ha apoderado de quienes tienen un lugar de privilegio tanto en Cuahutemallán como en Quisyan. El nefasto personaje dirige su creatividad hacia la búsqueda de crueles y sofisticadas estrategias empresariales

40 Galich, 265.

41 Ibid, 260.

42 Baczko, 147.

43 Ángel Gabilondo, "La creación de modos de vida", en Michel Foucault, Estética, ética y hermenéutica. Obras esenciales. Volumen III (Barcelona, España: Ediciones Paidós, 1999), 9-35.

44 El poder "circula, produce cosas, induce al placer, forma saber, produce discursos...". Michel Foucault, Estrategias de poder..., 48. 
que alimentan, pero también reorientan el deseo por violentar seres humanos. No hay quien se oponga a su proyecto de exterminio en Ciudad de Arriba.

Esos sujetos planos, vaciados de sentido de vida, incapacitados para comunicarse entre sí, inhiben esa capacidad humana de pensar de que nos habla Hannah Arendt en su reflexión sobre "la banalidad del mal" ${ }^{45}$ No se trata de la defensa de rígidos valores morales, sino de evaluar la experiencia a partir de criterios propios que responden a las transformaciones en la vida social y cultural. En palabras de Julia Kristeva, el mal radical que explora Arendt es "una manera histórica y políticamente 'cristalizada' de reducir a los hombres a la condición de 'superfluos': esto equivale a aniquilar su espontaneidad y su pensamiento para llevarlos a destruir sin escrúpulos una parte de la humanidad". ${ }^{46}$ En Tikal futura es difícil determinar si es más perturbador el sadismo ilimitado del indio Sacul o las masas movilizadas por el mercado en respuesta a estímulos eróticos que las inducen al abuso y la destrucción del otro individuo.

Las sangrientas represiones de la Guatemala del siglo XX no han perdido su vigor en el mundo de Tikal futura. El poder se orienta a la destrucción de los sectores de habitantes del mundo bajo como sujetos. Lo ideal es que sus cuerpos sean completamente manipulables. La imagen extrema de la aniquilación subjetiva se encuentra en esas jóvenes del mundo inferior que, sistemáticamente, son secuestradas, inoculadas con la droga, para ser convertidas repentinamente en dóciles y complacientes esclavas sexuales y, una vez utilizadas, regresadas a su mundo, sin que conserven memoria alguna de lo sucedido. El poder ha alcanzado su momento totalizador precisamente sobre el cuerpo de las mujeres. Como se ha podido apreciar en estas páginas, la subordinación sexual femenina es eje medular en la representación de la violencia. Recorre la obra, sugiriendo su potencial capacidad para generar y dinamizar otras expresiones del abuso sobre el cuerpo de la otra persona en las que, en forma metonímica, se expresa el erotismo de esa violencia fundacional. ${ }^{47}$

En una de las escenas de la obra, Apocalíptico, como lo hizo en otras ocasiones, muestra su buen humor jugando con la pronunciación del nombre de Klimowitz. Aludiendo a su afición por las mujeres y por el whisky. lo llama Mr. Klitoryswosky. En medio del ambiente festivo en que ambos se encuentran en el transcurso de la obra, Apocalíptico refiere a su proyecto de recreación de campos de guerrilleros para la diversión de turistas alimentados por descartables que

45 Hannah Arendt, "El pensar y las reflexiones morales", en Hannah Arendt, De la historia a la acción. (Barcelona, España: Ediciones Paidós, 1995), 109-137.

46 Julia Kristeva, El genio femenino 1. Hannah Arendt (Buenos Aires, Argentina: Ediciones Paidós, 2006), 162.

47 "The enslavement of women, combining both racism and sexism, preceded the formation of class...". Gerda Lerner, The Creation of Patriarchy (New York, EE. UU.: Oxford University Press, 1986), 213. Una reflexión sobre la apropiación de la sexualidad femenina como metáfora de las distintas formas de dominación del ser humano sobre la naturaleza y las sociedades colonizadas, puede encontrarse en: Anne McClintock, Imperial Leather. Race, Gender and Sexuality in the Colonial Contest (Londres, Inglaterra: Routledge, 1995), 1-17. 
portarán armas falsas; mientras los visitantes extranjeros los atacarán con armas de verdad. ${ }^{48}$ Asevera Apocalíptico: "se puede usted imaginar lo eufóricos que se pondrán nuestros clientes cuando sepan que pueden participar en auténticas cacerías de guerrilleros, ¡y matarlos! ¡Hasta masacres de aldeas con todo y niños podremos organizar! ¡Y sesiones de torturas en diferentes estilos y modalidades!"' ${ }^{49}$ De nuevo la obra sitúa a quien la lee en el escenario de las atrocidades cometidas por el ejército contra la población indígena a inicios de la década de 1980. Una guerra, parodiando el título de la obra de Brett, "sin batallas" en la que se alimentó el deseo por violar, torturar y aniquilar físicamente a un "enemigo" indefenso. Solo que, en el mundo narrado, la violencia como recreación no deviene exclusivamente de hombres preparados para matar, sino que es también alimentada por la empresa turística. A través del espectáculo, el simulacro en el que el "inofensivo" jugador del video vive el placer de aniquilar a los malvados, el telespectador, la satisfacción de ver caer bombas sobre los enemigos de Occidente se inocula el deseo por violentar a ese otro. Lo virtual y lo real se confunden traslapándose. ${ }^{50}$

Apocalíptico, conociendo la potencialidad de ese juego de espejos en el erotismo de la muerte, convierte el ritual de la masacre en un entretenimiento para visitantes provenientes de Quisyan, ese país del norte cuyo gobierno entrenó y dotó de armas a los grupos masacradores. Es innegable que él disfruta de la puesta en marcha de su proyecto. El indio Sacul erotiza la violencia al extremo de que esta pierde su razón de ser: un negocio turístico, para convertirse en un fin en sí misma. El ejército, en particular el batallón especialmente entrenado para la lucha contrainsurgente: los kaibiles, participan activamente en las labores organizativas de las masacres. ${ }^{51}$ La presencia de este temible cuerpo militar en el mundo del futuro, uno de los pocos referentes de la contemporaneidad que conserva su nombre, alimenta en la narrativa la continuidad entre el pasado y el porvenir, en una obra plena de metáforas sobre las dinámicas de la violencia en la llamada lucha contrainsurgente. En fin, se trata de toda una maquinaria orientada al aniquilamiento de "descartables" puesta en acción por una sociedad que promueve el erotismo de la violencia.

48 Tikal Futura devela las oscuras dimensiones de la empresa turística. Los inocentes grupos visitantes dispuestos a gastar amablemente su dinero en nuestros países han mostrado su rostro adusto en una Centroamérica donde la prostitución, el tráfico de mujeres y de niños se desarrollan como nunca antes en los espacios que visitan. Véase, por ejemplo: Asociación Catalana para la Infancia Maltratada, "Prostitución infantil y turismo", Futuros. Revista Trimestral Latinoamericana y Caribeña de Desarrollo Sustentable, 4 , n. 14 (2006): www.revistafuturas.info/futuras14/prostitucion_turismo.htm

49 Galich, 186.

50 "Es curioso y sintomático que un portavoz de Fort Bragg declarase orgulloso que soldados que regresaban de la guerra en Afganistán habían afirmado que su tarea allá había sido 'una imagen en espejo' de cuanto habían entrenado en Pineland", espacio donde el ejército estadounidense ha construido simulacros bélicos en el que sus soldados combaten con balas de salva, en apoyo a la buena ciudadanía contra las fuerzas del mal. Roger Bartra, Territorios del terror y la otredad (México, D.F.: Fondo de Cultura Económica, 2013), 13.

51 Galich, 212. 
Los grupos descartables, hechos prisioneros, serían recluidos en las Comunidades de Reforma Espiritual, Social y Auténtica (CRESA), institución que nos remite a las "aldeas modelo" donde el ejército recluyó a indígenas sobrevivientes de las masacres. En estas se estableció un estricto control sobre las vidas de sus habitantes, quienes, por la fuerza, trabajaron para la autosostenibilidad de estos espacios de reclusión, así como en las labores requeridas en el teatro de la guerra. Estos "guerrilleros plastificados" 52 de Tikal futura, remiten a las matanzas indiscriminadas de indígenas indefensos que el ejército disfrazó como producto de luchas contrainsurgentes. ${ }^{53}$ En CRESA hay una cámara "ubicada en un punto equidistante de todos y cada uno de los lugares de la comunidad... [un] ojo que todo lo ve". ${ }^{54}$ En las aldeas modelo el ejército ensayó un proceso de transformación identitaria de los sujetos recluidos que demandó un control permanente sobre ellos. Sus forzados habitantes fueron obligados a comunicarse en español, renunciar a sus prácticas religiosas, participar en la guerra contrainsurgente y escuchar charlas anti-comunistas..$^{55}$ Ese ojo que todo lo ve, es un ojo que controla para establecer disciplinas no productivas, sino destructivas, trasciende las aldeas modelo y se posesiona del mundo rural.

¿Es que los militares perpetradores de las masacres fueron monstruos ajenos del mundo humano? Tikal futura nos conduce a ubicar sus deseos de torturar y matar en la sociedad que habitan. La población civil no está exenta de responsabilidad. Ya no se trata solo de aquella minoría que participó directamente en las masacres, por decisión propia o por coacción de los militares. Tikal futura lleva a reflexionar hasta dónde puede llegar en su potencialidad destructiva un mundo social poblado de sujetos enajenados de su "capacidad de pensar", inmutables frente a la barbarie del ejército, portadores de un profundo racismo hacia aquellos en los que ven proyectada una parte odiada de sí.

Si esa otredad es considerada insignificante, no deja de ser desafiante para quienes en Ciudad de Arriba luchan desesperadamente por escalar posiciones sociales. Su reto reside en que en el cuerpo de los descartables se proyecta su propia abyección. Apocalíptico vive temeroso de que se llegue a saber que él procede de Ciudad de Abajo y el indio Sacul, a quien le resulta imposible ocultar su origen, es asediado por la percepción de que, quienes con él se relacionan, no pueden ocultar que en el fondo lo rechazan, aunque hipócritamente lo adulen. En ambos personajes la vergüenza es detonante de la violencia. Cuando Sacul asiste a las oficinas de Napichú, este reflexiona en lo siguiente: "el sabía que Sacul sabía que se moría de ganas por decirle en su cara ¡Indio, Indio! y recordarle su

52 Ibid, 218.

53 “.... es claro que el Alto Mando [del ejército] debía saber que los civiles, colaboradores y no colaboradores, no tenían armas, porque la guerrilla no tenía la capacidad de armarlos". Brett, Una guerra sin batallas..., 231.

54 Galich, 218.

55 Brett, Una guerra sin batallas..., 134-135. 
procedencia de Ciudad de Abajo, igual que el infame de Apocalíptico...". ${ }^{56}$ La vergüenza impulsa al odio y al deseo de aniquilamiento de aquellos que, cuando se les mira, hacen recordar ese origen abyecto. ${ }^{57} \mathrm{La}$ vergüenza acompaña el recuerdo de ese pasado "de un sentimiento de degradación, incluso de envilecimiento". ${ }^{58}$ También incita a imitar con la mayor perfección posible las prácticas y discursos de los poderosos, mientras inhibe el desarrollo de vínculos sociales entre iguales. En este sentido la vergüenza afianza el poder. En Ciudad Miseria, entre los sectores descartables que, viviendo en el extremo de la marginalidad, han organizado la insurgencia, se cultiva la memoria ancestral. ${ }^{59} \mathrm{El}$ orgullo de pertenencia al mundo indígena, en contraposición a la vergüenza, es elemento cohesionador que posibilita el surgimiento de la resistencia organizada. Pero este orgullo solo puede devenir de la memoria.

Cuanto más sofisticados y efectivos son los instrumentos de poder, más refinadas son las herramientas de resistencia. En Ciudad Miseria, donde los chips detectaban ya no solo las palabras sino también las señales manuales que sus habitantes crearon para lograr comunicarse subrepticiamente, “éstos, habían aprendido a hablar con los ojos, los cuales cambiaban el color, dependiendo de qué era lo que querían expresar". ${ }^{60}$ Una imagen más allá de lo creíble sugiere la imposibilidad de detener al ser humano en sus ansias de libertad. En el siguiente apartado exploramos cómo en Tikal futura ... se representa ese vínculo necesario entre la lucha por la libertad y la voluntad de dar vida a una subjetividad propia cuyas claves se encuentran en las profundidades del pasado.

\section{La memoria como esperanza}

El poder de Ciudad Arriba se ha propuesto despojar de la memoria a la sociedad bajo su dominio. La condena a la amnesia funciona en la obra como antídoto contra toda voluntad de cambio. Como sostiene ElieWiesel, "la memoria se halla indisolublemente unida a la identidad de manera que las dos se sustentan mutuamente". ${ }^{61}$ Sin memoria no puede existir el sujeto, pues de esta depende la transmisión de saberes, la capacidad de actuar y la reproducción misma del

56 Galich, 260.

57 Harris Memel-Fotê comenta el concepto de "negrofobia" creado por Franz Fanon para referirse a personas negras y mulatas que, identificadas con los europeos "manifiesta odio por su raza, por el continente de donde vienen sus ancestros esclavos, por su cultura...". Harris Memel-Fotê, "La memoria vergonzosa de la trata de negros y la esclavitud”, en: Elie Wiesel, et al., ¿Por qué recordar? (Buenos Aires, Argentina: Ediciones Granica S.A., 2007), 152.

58 Ibid, 147.

59 Galich, 116.

60 Ibid, 32 .

61 Elie Wiesel, "Prólogo”, en: Elie Wiesel, et al., ¿Por qué recordar? (Buenos Aires, Argentina: Ediciones Granica S.A., 2007), 12. 
vínculo social. ${ }^{62} \mathrm{El}$ sometimiento de la población de Ciudad de Abajo está acompañado de la destrucción de la memoria. La cultura indígena ha sobrevivido en este mundo del futuro en memorias fragmentadas. El juego de pelota, en versión bastante modificada conserva su nombre, aunque sus sentidos han sido trastocados $\mathrm{y}$, los referentes culturales que otrora le dieron sustento, se han perdido.

Por otra parte, referentes del mundo maya, como las ruinas de Tikal, han sido tomados para representar la magnificencia del poder, enajenando a quienes la crearon. De esta forma, "Tikal futura era una colosal estructura de acero, vidrio y granito tallado. Era una réplica aumentada hasta el infinito de un antiquísimo templo, de una hipotética civilización, que según las leyendas más fantásticas le atribuían la capacidad de leer los astros y de haber inventado el cero" ${ }^{63} \mathrm{El}$ pasado indígena, violentamente expropiado a sus descendientes, es refuncionalizado al servicio del poder, creador de una memoria avasalladora, capaz de manipular $\mathrm{y}$, si es del caso, destruir narrativas cimentadas en evidencias históricas. Integrando segmentos incoherentes de ese pasado, se crea una atmósfera atractiva para el turismo. Tikal futura tenía:

\begin{abstract}
"estructuras de forma piramidal truncas, comunicadas entre sí por varias escaleras electrónicas disimuladas entre vegetación plástica. Había muchas reproducciones y flores exóticas de plástico; lo mismo de aves silvestres y canoras, cuyo canto era reproducido por pistas de sonido láser". ${ }^{64}$
\end{abstract}

Mediante la manipulación de elementos culturales y naturales, los vestigios del pasado son exotizados y, por tanto, despojados de los sentidos que les otorgaron quienes construyeron y habitaron Tikal. En los museos metropolitanos y en aquellos creados por las nacientes naciones, los objetos arqueológicos han sido, sistemáticamente, enajenados de la complejidad cultural que los envuelve. ${ }^{65}$ También la antropología ha contribuido a este proceso al folclorizar las manifestaciones artísticas del mundo indígena. Esos rastros culturales llegan a observarse a través de manifestaciones visuales extrañas, incomprensibles, desarticuladas entre sí. En el tiempo que le correspondió vivir a Galich, afirma Santiago Bastos: "lo maya' no pasa de las ceremonias, el folklore o el turismo,

62 François Heritier, "Preámbulo. Casos de memoria", en Elie Wiesel, et al., ¿Por qué recordar? (Buenos Aires, Argentina: Ediciones Granica S.A., 2007), 125-126.

63 Galich, 163.

64 Ibid, 274.

65 "Although Brithis archaeologists, travelers, and government officials justified their plunder by invoking the rhetoric of cultural salvage (rescuing artifacts from the 'abandoned' sites where they lay), such actions stripped away both the objects and their meanings in the symbolic systems in which they functioned". Robert D. Aguirre, Informal Empire. México and Central America in Victorian Culture (Minneapolis, EE. UU.: University of Minnesota Press, 2002), XXIII. 
mientras 'los indígenas' y 'los campesinos' son otra cosa totalmente diferente". ${ }^{66}$ Ese "extrañamiento" frente al otro ser, característico de la mirada colonial, convierte a los sujetos en objetos al atribuir el sentido de sus vidas a la representación de expresiones culturales exóticas, es decir, enajenadas de su experiencia vital. ${ }^{67}$ Ellos solo tienen existencia para satisfacer el deseo del visitante por lo raro, lo diferente y sensual.

La pérdida de sentido de las huellas del pasado también domina a las descendencias mismas de las sociedades indígenas. En Ciudad de Abajo esos rastros del mundo ancestral que aún sobreviven están vaciados de su historia. Los representantes del poder de Ciudad de Arriba, doscientos años atrás, cuando se firmaron los Acuerdos de Paz que condujeron a la segregación espacial de la sociedad, procedieron a destruir los archivos alegando que ello era necesario para garantizar la paz. ${ }^{68}$ Estas líneas nos remiten, inevitablemente, a las amnistías decretadas, con recurrencia, en el mundo republicano europeo de los siglos XIX y XX así como en los países de América Latina que, a partir de la década de 1980, han vivido procesos de transición de la dictadura a la democracia. La "amnistía", concomitante con la amnesia, propone la paz a partir de la impunidad y el olvido. ${ }^{69}$ La paz sin memoria se presenta en la narrativa como la paz que se mantiene a partir de la destrucción del sujeto, permitiendo que el poder se asiente cómodamente, sin desafíos. Entonces, la ominosa historia estará allí, al acecho, posesionándose de una sociedad cuya amnesia le impide defenderse de su pasado.

No obstante, la memoria sobrevive entre un pequeño grupo de seres superiores como la abuela Cané, depositaria de la narrativa histórica de los pueblos Yama. Negarse al olvido es "una apelación a un "nunca más"". ${ }^{70}$ Las historias de dolor que se pierden en el tiempo, regresan con su energía de violencia inalterada. El proyecto de Apocalíptico, matar gente por distracción, por deporte, no es descabellado en un país donde el ejército, con la colaboración de civiles, masacró cientos de poblados indígenas indefensos sin que hasta hoy haya habido

66 Santiago Bastos, "La política maya en la Guatemala posconflicto", en Bastos y Brett, El movimiento maya..., 15.

67 Sostiene Andrew Zimerman. refiriéndose a uno de los pioneros de la antropología alemana, Rudolf Virchow, que para él “objects existed independently of historians...”. Andrew Zimmerman, Anthropology and Antihumanism in Imperial Germany (Chicago, EE. UU.: The University of Chicago Press, 2001), 49. Por supuesto, en el siglo XX desde la antropología se ensayan miradas que buscan comprender los sentidos de vida de las diversas culturas. Sin embargo, es la visión antropológica que construye imágenes estereotipadas y simplificadas de la otredad, la que ha contribuido a formar los referentes del otro entre habitantes del mundo colonial y de los estados nación del sur. Véase, por ejemplo: Clifford Geertz, El antropólogo como autor (Barcelona, España: Ediciones Paidós, 1988).

68 Galich, 250.

69 Henry Rousso, "El estatuto del olvido", en Elie Wiesel, et al., ¿Por qué recordar? (Buenos Aires, Argentina: Ediciones Granica S.A., 2007), 89.

70 Elizabeth Lira, "Memoria y olvido", en Volver a la memoria, (comp.) Raquel Olea y Olga Grau (Santiago, Chile: LOM Ediciones, 2001), 51. 
justicia. El recuerdo es, indudablemente, "un primer paso para luchar contra la banalización de la muerte y el terror". ${ }^{71}$ En la Guatemala contemporánea, las voces que pugnan contra la impunidad son débiles frente a quienes apuestan por el olvido. ${ }^{72}$

La abuela tiene como misión conservar la historia para transmitirla, impidiendo que la última posibilidad de resistencia sea aniquilada. También el pequeño grupo de descartables que integran el Ejército Revolucionario de Liberación de Ciudad de Abajo (ERLCIA), representados en Vitz y Zacté, ha logrado posesionarse de recuerdos de luchas pasadas para construir una resistencia organizada.

La visión cíclica de la historia, característica del mundo ancestral mesoamericano, se cuenta una y otra vez. Tzvetan Todorov analiza el efecto de ese tiempo circular en el proceso de conquista. Asevera que la concepción del tiempo de mayas y aztecas donde "pasado y futuro son lo mismo" y "profecía es memoria"73 debilitó la capacidad de respuesta a la conquista española. Los grupos invasores, con una visión lineal del tiempo, estaban mejor preparados para enfrentar los imprevistos de un proceso que carece de antecedentes. Por el contrario, en la obra de Galich, la única posibilidad de construir resistencias efectivas frente a ese proceso de conquista, de derrotas, que se repiten a través de la historia, es aprehendiendo esa circularidad del tiempo. Precisamente allí se encuentra la fortaleza de la narrativa histórica.

División y sometimiento convierten la historia del mundo indígena en una constante. La primera posibilitó la conquista española, así como la derrota de insurrecciones posteriores. El mundo vivido es un producto de esta historia cíclica y el reto es quebrar ese sino trágico. Ejércitos de informantes pululaban en Ciudad Miseria y Ciudad de Arriba ${ }^{74}$ formas de control social alegóricas de las dictaduras del siglo XX y, en particular, de la dinámica del poder en la historia de Centroamérica. En Guatemala, durante el conflicto armado, la violencia de las fuerzas represivas se complementa con la participación de colaboradores civiles, estrategia destinada a dividir las comunidades y hacer explotar la violencia en su interior, debilitando toda capacidad de resistencia. ${ }^{75}$ Con la creación de las Patrullas de Autodefensa Civil, el ejército involucró a civiles del campo en la guerra contrainsurgente, y generó profundas fisuras en las comunidades campesinas. ${ }^{76}$

$71 \mathrm{Ibid}, 51$. ¿Acaso puede la sociedad guatemalteca reconciliarse, olvidando su reciente pasado? ... ¿Pueden seguir conviviendo en este país los criminales de guerra y sus víctimas, dentro de una total impunidad de los primeros y una absoluta impotencia de los segundos?”. Edgar Alfredo Balsells Tojo, Olvido o memoria. El dilema de la sociedad guatemalteca (Guatemala, Guatemala: FlACSO, 2009), 23.

72 Ibid, 30.

73 Tzvetan Todorov, The Conquest of America (New York, EE. UU.: Harper Torchbooks, 1984), 85.

74 Galich, 59.

75 Una reflexión sobre la incorporación de civiles en la represión como estrategia para desarticular el mundo subalterno se encuentra en: Patricia Alvarenga, Cultura y ética de la violencia. El Salvador (1880-1932) (San Salvador, El Salvador: Concultura, 2006), capítulo V.

76 Véase Brett, Una guerra sin batallas..., 132. 
Además, sostiene Brett refiriéndose al conflicto armado en la década de 1980: "el ejército manipuló e intensificó las divisiones históricas, principalmente en términos étnicos y religiosos... y así logró destruir, militarizar y brutalizar el tejido social de las comunidades rurales". ${ }^{77}$

En esa visión crítica del pasado del mundo indígena se encuentran las potencialidades subversivas. La idealización de la historia, en cambio, puede resultar poco efectiva para orientar las acciones futuras. ${ }^{78}$ La abuela Cané narra las luchas internas entre los pueblos indígenas que preceden la conquista. Estas, al llegar el momento del enfrentamiento con los grupos españoles, tienen efectos desastrosos. Tikal futura remite, alegóricamente, a esas fracturas en el mundo subalterno a partir del drama de la conquista que una y otra vez se repite. En el proceso de reconciliación que culmina con los Acuerdos de Paz de 1996, no solo el ejército se mostró reticente a aceptar la creación de una Comisión de la Verdad. La guerrilla también concibió esa instancia como amenaza. ${ }^{79}$ Sostiene Brett que las investigaciones que revelan las sistemáticas violaciones a los derechos humanos llevados a cabo por instancias como la Comisión para el Esclarecimiento Histórico de las Naciones Unidas, "no son conocidas y ni siquiera aceptados por muchos miembros de la sociedad guatemalteca, y todavía la sociedad no conoce su propia historia, incluyendo los acontecimientos del conflicto armado interno". ${ }^{80}$

Sin embargo, ha habido algunos avances en la lucha por crear conciencia sobre la historia reciente del país. Señala Hale, refiriéndose a la experiencia guerrillera que, a partir de la firma de los Acuerdos de Paz "los recuerdos empezaron a fluir con mayor libertad". ${ }^{81}$ No obstante, ello ocurre precisamente cuando, irónicamente, reclamar una identidad revolucionaria ha perdido su potencial subversivo. Más bien, quien se atreve a hacerlo, corre el riesgo de "parecer fuera de contacto con la realidad, extraño o levemente absurdo". ${ }^{82}$ Es decir, no se trata simplemente de "recordar" sino de convertir el recuerdo en efectivo instrumental para diseccionar el presente. Como lo sostiene Pilar Calveiro, "la memoria ordena pero lo hace de una manera distinta al relato histórico. Trae al presente las ofensas, las heridas, para impedir su 'desaparición' e interrumpir, de alguna manera, la impunidad del poder". ${ }^{83}$

77 Ibid, 227.

78 Una crítica a escritos de intelectuales mayas que idealizan y petrifican el pasado se encuentra en Hugo Cayzac, "Las organizaciones mayas en la transición: Del modelo republicano hacia un proyecto político multicultural democrático", en Bastos y Brett, El movimiento maya ..., 156.

79 Balsells, 93.

80 Brett, Una guerra sin batallas..., 246.

81 Hale, 114.

82 Ibid, 145.

83 Pilar Calveiro, "La memoria como futuro", Actuel Marx Intervenciones (Chile) 6 (enero-junio 2008): 63. "El recuerdo es un nudo de significaciones en trance que se deshacen y rehacen bajo las circunstancias de un presente que las selecciona y las recombine de acuerdo a sus urgencias críticas". Nelly Richard, "Recordar el olvido", en Volver a la memoria, (comp.) Raquel Olea y Olga Grau (Santiago, Chile: LOM Ediciones, 2001), 20, Las cursivas son del texto. 
En la memoria están las claves de la transformación de la historia. En ese ejercicio hermenéutico de "memoria y olvido, interpretación y construcción" 84 se teje una narrativa del pasado con vocación de futuro. La abuela Cané, al igual que los sacerdotes del mundo indígena antiguo, posee el don de la profecía, el don de leer el futuro en el pasado Los tukuches, familia quiché, codiciaban las tierras de los Akahales y el 18 de agosto de 1497 los atacan. Los reyes cakchiqueles, soberanos de ambos, intervienen para lograr la paz. No obstante, el soberbio príncipe tukuche Cay Hunahpú se fortalece atrayendo a sus filas a miembros de la nobleza cakchiquel, a quienes intenta arrancar el poder. Pero los tukuches son vencidos y luego masacrados. ${ }^{85}$ Esta historia se repite constantemente. Cambian los protagonistas, pero división y traición son una constante en las luchas de los pueblos indígenas. La historia de la conquista que narra la abuela es reproducida por Vitz, pero en un momento histórico distante: los cabek, familia cakchiquel, se insurreccionaron contra los señores de Ablabix -quienes representan a los descendientes de españoles-, sus abuelos los tukuches se negaron a ir al combate creyendo en las promesas del poderoso adversario. La traición no se hizo esperar. Pero esta no devino exclusivamente de los Ablabix: en sus filas participaron guerreros tukuches. ${ }^{86} \mathrm{El}$ lector o lectora deduce que esta historia se desarrolla en un tiempo bastante cercano al representado en la obra, solamente por la breve alusión a la tecnología militar moderna: los Ablabix y los tukuches poseían carros movidos por electricidad nuclear. ${ }^{87}$ Pero acto seguido la narración de estos acontecimientos nos ubica en el tiempo de la conquista, cuando ocurre "la primera mezcla de nuestras sangres... días tristes en que nuestras mujeres se aparearían a la fuerza con los de Ablabix, creando así una nueva raza. De ella venimos los de Ciudad Miseria y de ella vienen también los de Ciudad Superior". ${ }^{88}$

Rompiendo la linealidad temporal, la narración regresa una y otra vez al mismo acontecimiento. El acto de la conquista se repite en una aspiral incesante. La confusión de personajes, batallas, ritualidades, ubica en una historia que, pese a las transformaciones materiales que le acompañan, se reproduce en lo esencial: la división y traición que deviene del seno de los grupos vencidos garantiza una y otra vez el triunfo de los adversarios y, más allá de estos, como se aprecia en la obra a través de Apocalíptico y el indio Sacul, la reproducción del poder. Pasado, presente y futuro unidos por un destino común que en la obra no se logra trascender, aunque permanece la esperanza de lograrlo. La abuela se pregunta: “¿Será que estamos condenados a seguir repitiendo nuestras desgracias?" ${ }^{99} \mathrm{Sin}$ embargo, en la narrativa el destino se presenta también como esperanza. Los

84 Calveiro, 66.

85 Galich, 78-81.

86 Ibid, 59-60.

87 Ibid, 60.

88 Ibid, 60.

89 Ibid, 187. 
personajes deben conocer la historia para saber cómo actuar en ella. La señora Linmá, viuda de uno de los líderes de la última insurrección, que tuvo lugar cincuenta años atrás, se dirige a Ix diciéndole: “Tu sí que debes saber tu destino. No para evadirlo porque nadie lo puede hacer. No. Para cumplirlo a cabalidad. Tu responsabilidad es grande entre los de nuestra estirpe", ${ }^{90}$

\section{Conclusión}

La abuela Cané estaba dormida cuando se le presentó su nahual y le dijo:

"Lo que queremos de ti, abuela Cané, es que pulas las letras para que adquieran el filo del pedernal, para que rasguen la tela negra que cubre los ojos de la gente y así puedan ver la faz de la Tierra, la faz de la Luna, la faz del Sol, la faz del Tiempo que es lo único verdadero". ${ }^{91}$

La reflexión literaria, entendida en su acepción más amplia como reflexión discursiva, permite rasgar esa "tela negra que cubre los ojos", pero no lo hace de un tirón como lo han supuesto las dicotomías ideológicas, sino a partir de un proceso de reflexión sobre lo que somos como individuos y como sociedades. Tikal futura... nos convoca a vernos como sujetos construidos históricamente y, a la vez, a aprehender la historia como un instrumento fundamental para objetivarnos a nosotros mismos y valorar los caminos posibles. En la conciencia de la historia está la salvación posible. La memoria permite el despliegue de un futuro que, de acuerdo con Calveiro, "como promesa, como espera y esperanza, es el tiempo de la resistencia". ${ }^{92}$ Tikal futura, si bien es una obra distópica, como lo sostiene Werner Mackenbach, también se abre a la utopía, a la esperanza en quienes, desde la exclusión, logran defender su memoria y articular una reflexión sobre su experiencia. ${ }^{93}$

Encontrar las claves que ofrece la historia es un proceso hermenéutico que la abuela Cané va tejiendo a partir del tesoro que ella guarda celosamente, pues contiene el secreto de la salvación: la herencia textual. La reflexión sobre lo que fue y lo que podría haber sido permite al sujeto adquirir esa profundidad interior que lo prepara para desafiar el poder. Imaginamos con Galich, la Ciudad de Arriba poblada de individuos encerrados en sí mismos, temerosos; pero también incapaces de comunicarse entre sí y con el mundo circundante, absortos frente a la oferta del mercado, indiferentes ante decisiones políticas capaces de llevar al aniquilamiento masivo de seres humanos; en suma, sujetos ideales en un mundo donde el poder instaura el sinsentido, la muerte, el terror como elementos

90 Ibid, 239.

91 Ibid, 253-254.

92 Calveiro, 64.

93 Véase la contraportada de Tikal Futura... 
cosustanciales de su reproducción misma. Apocalíptico y el negro Sacul, huyendo de sí mismos, atribuyen a los otros seres aquello de sí que avergüenza, para despojarse de la temida abyección; pero esta, irremediablemente, les acompaña y se convierte en una fuerza interior que los induce al mal, a la destrucción.

La impresionante maquinaria de poder que controla Ciudad de Abajo no ha logrado destruir la solidaridad humana y la capacidad reflexiva de sus habitantes. Vitz y Zacté, hundidos en las profundidades de las cloacas, lejos de haber sido despojados de su humanidad, han logrado, en los términos de Arendt, "pensar" y, así, reivindicarse en su experiencia extrema de exclusión y abominación.

Tikal futura sitúa a quien lee en una contemporaneidad que abre posibles rutas para el encuentro de la sociedad guatemalteca; pero estas, a la vez, se desdibujan frente a las fuerzas del pasado, que amenazan con arrasar lo poco que se ha cimentado. El liderazgo que podría incidir en una real democratización del país repite tercamente el ciclo histórico estableciendo alianzas en beneficio de las instituciones hegemónicas. El rostro horripilante del racismo se maquilla; pero, posiblemente, no por ello ha abandonado su potencial destructivo. Sin embargo, quizá si colocamos el punto de mira en espacios poco visibilizados del movimiento social, podríamos advertir que resistencias nacientes abren de nuevo el horizonte de la esperanza. 